\title{
AKTIVITAS REPELAN MINYAK ATSIRI BIJI PALA (Myristica fragrans Houtt.) PADA NYAMUK Aedes aegypti
}

\author{
REPELLENT ACTIVITY of NUTMEG ESSENTIAL OIL (Myristica \\ fragrans Houtt.) on Aedes aegypti
}

\author{
Lina Widiyastuti*, Azis Ikhsanudin, Noorlina \\ Fakultas Farmasi, Universitas Ahmad Dahlan Yogyakarta \\ *Penulis Korespodensi : lina.widiyastuti@pharm.uad.ac.id
}

\begin{abstract}
ABSTRAK
Telah dilakukan penelitian untuk menguji aktivitas repelan minyak atsiri biji pala terhadap nyamuk Aedes aegipty betina. Repelan yang banyak beredar di pasaran yaitu repelan sintetik yang dapat memberikan dampak negatif untuk kesehatan karena umumnya mengandung Diethyltoluamide atau DEET. Minyak atsiri biji pala mengandung eugenol, metil eugenol, elemisin miristisin, $\alpha$-pinena, dan $\beta$-pinena yang dapat digunakan sebagai repelan. Penelitian bertujuan untuk mengetahui pengaruh konsentrasi minyak atsiri biji pala terhadap iritasi dan aktivitas repelan. Uji dilakukan pada 6 konsentrasi minyak biji pala yaitu 4, 6, 8,10, 12\% (v/b) dan kelompok kontrol. Pengujian meliputi uji $\mathrm{pH}$, iritasi, dan aktivitas repelan. Aktivitas repelan dianalisis menggunakan SPSS dengan ANOVA dan dilanjutkan dengan $L S D$ pada taraf signifikansi 95\%. Hasil penelitian menunjukkan $\mathrm{pH}$ masing-masing konsentrasi adalah 6. Iritan bersifat sangat ringan. Aktivitas repelan dari 6 seri konsentrasi tersebut berturut-turut adalah 43,95; 373,56; 758,03; 1167,41; 1950,98 dan 4,29 detik. Berdasarkan hasil yang diperoleh disimpulkan bahwa minyak atsiri biji pala mempunyai aktivitas repelan terbesar terhadap nyamuk Aedes aegypti betina pada konsentrasi $12 \%(\mathrm{v} / \mathrm{b})$ selama 1950,978 detik dan iritan yang sangat ringan.
\end{abstract}

Kata kunci : Minyak atsiri biji pala (Myristica fragrans Houtt.), nyamuk Aedes aegypti, repelan

\section{ABSTRACT}

This research was conducted to examine the repellent activity of nutmeg essential oil to Aedes Aegipty mosquitoes. Most repellent in the market is synthetic replication that can give negative results for health because it generally contains DEAT. The essential oil of nutmeg contains eugenol, methyl eugenol, elemisin myristisin, $\alpha$-pinena, and $\beta$-pinene which can be used as repellent. Research was also aimed to know the concentration of essential oil of nutmeg to irritation and repellent activity. The test was performed on 6 nutmeg oil concentrations is 4\%, 6\%, 8\%, 10\%, 12\% (v/b) and control group. The tests include $\mathrm{pH}$, irritation, and repellent activity test. The repellent activity was analyzed using SPSS with ANOVA and continued with LSD at 95\% significance level. The results 
showed that the $\mathrm{pH}$ of each concentration was 6. The irritant was very mild. Repellent activities of the 6 series are 43.952 seconds, 373.556 seconds, 758.032 seconds, 1167.41 seconds, 1950.978 seconds and 4.292 seconds. The results obtained concluded that nutmeg essential oil has the largest repellent activity against Aedes aegypti at 12\% concentration $(\mathrm{v} / \mathrm{b})$ with 1950,978 seconds and very mild irritant.

Keywords: Nutmeg essential oil (Myristica fragrans Houtt.), Aedes aegypti mosquito, repellen.

\section{PENDAHULUAN}

Menurut Kementerian Kesehatan Republik Indonesia (2010) demam berdarah dengue (DBD) merupakan salah satu masalah kesehatan masyarakat Indonesia, karena jumlah penderita dan luas penyebarannya semakin bertambah seiring dengan meningkatnya mobilitas dan kepadatan penduduk. Vektor utama yang berperan dalam penyebaran penyakit demam berdarah yaitu nyamuk Aedes aegypti.

Menurut Kementerian Kesehatan Republik Indonesia (2015) pencegahan penyakit demam berdarah dapat dilakukan dengan berbagai cara, salah satunya yaitu dengan menggunakan obat nyamuk atau anti nyamuk. Repelan yaitu bahan-bahan yang mempunyai kemampuan untuk menjauhkan serangga dari manusia, sehingga gigitan serangga dapat dihindari (Yuniarsih, 2010). Repelan yang banyak beredar di pasaran yaitu repelan sintetik yang dapat memberikan dampak negatif untuk kesehatan. Dampak negatif tersebut disebabkan karena umumnya mengandung Diethyltoluamide atau DEET (Yoon et al., 2015).

Salah satu efek negatif dari Diethyltoluamide atau DEET yaitu dapat menyebabkan terjadinya iritasi pada kulit (Robbins dan Cherniack, 1986). Untuk menghindari efek samping negatif tersebut, diperlukan repelan berbahan alami yang aman untuk kesehatan dengan menggunakan biji pala. Biji pala mengandung minyak atsiri yang memiliki aroma khas dan mudah menguap. Minyak atsiri biji pala diketahui mengandung $\alpha$-pinena dan $\beta$-pinena yang memiliki aktivitas repelan (Agoes, 2007 dan Geetha dkk, 2014). Selain itu aktivitas repelan dari minyak atsiri biji pala juga ditunjukkan pada kandungan eugenol, metil eugenol,elemisin dan miristisin (Du dkk, 2014). Penelitian ini bertujuan untuk mengetahui aktivitas minyak atsiri biji pala (Myristica fragrans Houtt.) sebagai repelan alami. 


\section{METODE PENELITIAN}

\section{Alat dan Bahan}

Alat

Alat yang digunakan pada penelitian ini adalah: sangkar nyamuk dengan ukuran $20 \times 20 \times 20 \mathrm{~cm}$ dengan lubang sirkuler berdiameter $15 \mathrm{~cm}$, seperangkat alat gelas dan alat yang umum ada di laboratorium.

Bahan

Bahan uji yang digunakan dalam penelitian ini adalah: biji pala (Myristica fragrans Houtt) yang diperoleh dari Maluku. Hewan uji yang digunakan yaitu Aedes aegypti betina dan kelinci albino. Umur nyamuk yang digunakan yaitu seminggu atau 7 hari. Bahan kimia yang digunakan terdiri dari aquadest, $\mathrm{KI}, \mathrm{Na}_{2} \mathrm{SO}_{4}$, tween 80 , dan span 80 .

\section{Jalannya Penelitian}

Uji pH

Uji pH dilakukan sebelum dilakukan uji iritasi dan uji repelan emulsi minyak atsiri biji pala menggunakan kertas $\mathrm{pH}$ dengan cara mencelupkan kertas $\mathrm{pH}$ pada sediaan.

Uji iritasi

Selanjutnya dilakukan uji iritasi menggunakan hewan uji kelinci albino. Sebelum pengujian hewan uji diaklimatisasi di ruang percobaan selama kurang lebih 5 hari. Kemudian 24 jam sebelum pengujian bulu hewan dicukur pada daerah punggung dengan luas kurang lebih $10 \times 15 \mathrm{~cm}$ sebagai tempat pemaparan sampel uji. Punggung hewan yang telah dicukur dibagi menjadi 6 bagian dan sampel dipaparkan pada kulit seluas $2 \times 3 \mathrm{~cm}^{2}$. Lalu ditutup selama 4 jam dengan kasa dan diplester menggunakan plester yang bersifat non iritan. Setelah itu kasa dan plester dibuka kemudian residu sampel dihilangkan dengan air. Selanjutnya dilakukan pengamatan pada jam ke 1, 24, 48, dan 72 jam setelah pembukaan plester. Evaluasi pengamatan hasil uji iritasi dilakukan dengan rumus 1 .

$$
\text { Indeks iritasi primer }=\frac{\mathrm{A}-\mathrm{B}}{\mathrm{C}} \text {. }
$$

\section{Keterangan :}

A : Jumlah skor eritema dan udema seluruh titik pengamatan sampel pada jam ke 24, 48 dan 72 dibagi jumlah pengamatan

B : Jumlah skor eritema dan udema seluruh titik pengamatan kontrol pada jam ke 24, 48 dan 72 dibagi jumlah pengamatan

C : Jumlah hewan

Nilai rata-rata dari respon iritasi pada kelinci dikategorikan seperti tersaji pada Tabel I. 
Tabel I. Indeks Iritasi Primer (BPOM, 2014)

\begin{tabular}{cl}
\hline Nilai rata-rata & \multicolumn{1}{c}{ Kategori respon } \\
\hline $0,0-0,4$ & Sangat ringan (negligible) \\
$0,5-1,9$ & Iritan ringan $($ slight $)$ \\
$2,0-4,9$ & Iritan sedang (moderate) \\
$5,0-8,0$ & Iritan kuat (severe) \\
\hline
\end{tabular}

Uji aktivitas repelan

Uji aktivitas repelan dilakukan untuk mengetahui konsentrasi minyak atsiri yang paling efektif digunakan sebagai repelan. Dua puluh ekor nyamuk Aedes aegypti betina yang sudah dipuasakan sehari sebelum dimasukkan dalam sangkar pengujian. Sediaan minyak atsiri biji pala dioleskan pada pergelangan tangan sebanyak 1,5 g kemudian pergelangan tangan dimasukkan kedalam sangkar dan diamati lama waktu penolakan hingga nyamuk menempel pada pergelangan tangan probandus. Proses pengujian dilakukan menggunakan mekanisme kerja yaitu :

1. Repelan berefek kurang dari 20 menit

Pergelangan tangan dimasukkan dalam sangkar selama 1 menit dengan selang waktu 5 menit. Pengujian dihentikan bila nyamuk telah menempel untuk pertama kalinya.

2. Repelan berefek antara 20 menit hingga 4 jam

Pergelangan tangan dimasukkan dalam sangkar selama 1 menit dengan selang waktu 15 menit. Pengujian dihentikan bila nyamuk telah menempel untuk pertama kalinya.

3. Repelan berefek lebih dari 4 jam

Pergelangan tangan dimasukkan dalam sangkar selama 1 menit dengan selang waktu 1jam. Pengujian dihentikan bila nyamuk telah menempel untuk pertama kalinya (Fradin dan Day, 2002).

Analisis Data

Data yang diperoleh dianalisis menggunakan SPSS (Statistical Product and Services Solution). Untuk mengetahui homogenitasnya digunakan uji Levene, sedangkan untuk mengetahui normalitasnya digunakan uji Kolmogorof Smirnov. Data yang diperoleh berupa data parametrik maka dilanjukan dengan uji ANOVA (Analysis of Varian). Pengujian dilakukan dengan taraf kepercayaan 95\%. Selanjutnya dilakukan uji 
beda nyata yaitu dengan pos hocLSD (least significance difference) untuk mengetahui apakah ada perbedaan pada tiap kelompok.

\section{HASIL DAN PEMBAHASAN}

1. Uji pH

Uji $\mathrm{pH}$ dilakukan untuk mengetahui $\mathrm{pH}$ dari formula yang dibuat. $\mathrm{pH}$ perlu dipastikan sama dengan $\mathrm{pH}$ kulit agar tidak menyebabkan iritasi. Hasil pengujian $\mathrm{pH}$ sediaan disajukan pada Tabel II.

Tabel II. Uji pH sediaan

\begin{tabular}{cc}
\hline Konsentrasi $(\% \mathbf{v} / \mathbf{b})$ & $\mathbf{p H}$ \\
\hline 4 & 6 \\
6 & 6 \\
8 & 6 \\
10 & 6 \\
12 & 6 \\
Kontrol & 6 \\
\hline
\end{tabular}

Dari Tabel II menunjukkan minyak atsiri biji pala konsentrasi 4, 6, 8, 10, $12 \%$ (v/b) dan kontrol memiliki $\mathrm{pH}$ masing-masing adalah 6. Tabel II menunjukkan penambahan minyak atsiri biji pala tidak menyebabkan perubahan nilai $\mathrm{pH} . \mathrm{pH}$ kulit berkisar antara 4,5-6,5 (Tranggono dan Latifah, 2007). Hasil pengujian $\mathrm{pH}$ yang diperoleh menunjukkan bahwa minyak atsiri biji pala memiliki $\mathrm{pH}$ yang memenuhi batasan pada pH kulit.

\section{Uji iritasi}

Uji iritasi dilakukan untuk mengetahui kemampuan minyak dalam mengiritasi.Uji iritasi yang terjadi selanjutnya dihitung dengan menggunakan rumus indeks iritasi primer. Hasil pengujian dapat dilihat pada Gambar 1. 


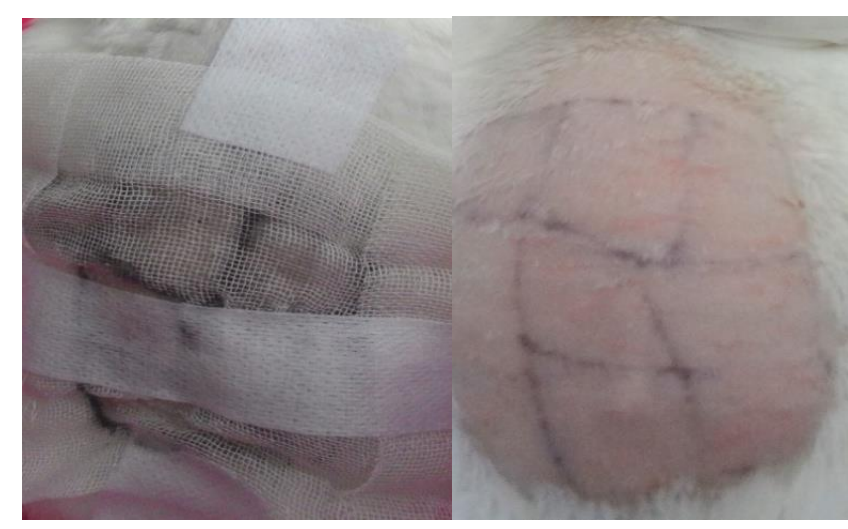

(a)Sebelum pengamatan (b) Pengamatan jam ke-72

Gambar 1. Hasil uji iritasi

Hasil pengamatan menunjukkan bahwa formula 1, 2 dan 3 dengan minyak atsiri biji pala konsentrasi 4, 6 dan $8 \%$ (v/b) tidak terlihat adanya eritema dan udema. Formula 4 dan 5 dengan minyak atsiri biji pala konsentrasi 10 dan 12\% (v/b) menunjukkan adanya eritema. Adapun hasil perhitungan indeks iritasi primer disajikan pada Tabel III.

Tabel III. Skoring Indeks Iritasi Primer

\begin{tabular}{lcl}
\hline Formula & Indeks Iritasi Primer & Kategori \\
\hline F1 & $-0,037$ & - \\
F2 & $-0,037$ & - \\
F3 & $-0,037$ & - \\
F4 & 0 & Sangat ringan \\
F5 & 0,074 & Sangat ringan \\
\hline
\end{tabular}

Keterangan :

F1 : Minyak atsiri biji pala konsentrasi $4 \%(\mathrm{v} / \mathrm{b})$

F2 : Minyak atsiri biji pala konsentrasi $6 \%(\mathrm{v} / \mathrm{b})$

F3 : Minyak atsiri biji pala konsentrasi $8 \%(\mathrm{v} / \mathrm{b})$

F4 : Minyak atsiri biji pala konsentrasi $10 \%(\mathrm{v} / \mathrm{b})$

F5 : Minyak atsiri biji pala konsentrasi $12 \%(\mathrm{v} / \mathrm{b})$

Hasil perhitungan menggunakan rumus indeks iritasi primer menunjukkan hasil negatif pada formula 1, 2, dan 3 dengan minyak atsiri biji pala konsentrasi 4, 6 dan 8\% (v/b). Pada formula 4 dengan minyak atsiri biji pala konsentrasi $10 \%$ (v/b) indeks iritasi primer ditunjukkan pada nilai 0 dan pada formula 5 dengan minyak atsiri biji pala konsentrasi $12 \%(\mathrm{v} / \mathrm{b})$ indeks iritasi primer ditunjukkan pada nilai 0,074. Menurut BPOM (2014) Tabel III menunjukkan bahwa formula 1, 2, dan 3 dengan minyak atsiri 
biji pala konsentrasi 4, 6 dan 8\% (v/b) tidak dapat dikategorikan ke dalam respon iritasi dikarenakan hasil perhitungan yang negatif. Hasil negatif tersebut diperoleh karena kontrol yang digunakan memiliki skoring iritasi yang lebih besar dibandingkan perlakuan. Pada formula 4 dan 5 dengan minyak atsiri biji pala konsentrasi 10 dan $12 \%$ (v/b) menunjukkan bahwa iritasi yang dihasilkan dikategorikan bersifat sangat ringan dengan nilai rata-rata respon iritasi sebesar 0,0-0,4.

3. Uji aktivitas repelan

Hasil uji aktivitas repelan disajikan pada tabel IV.

Tabel IV. Hasil Uji Aktivitas Repelan Minyak Biji Pala

\begin{tabular}{cc}
\hline Formula & Uji Aktivitas Repelan X \pm SD (detik) \\
\hline F1 & $43,9 \pm 5,7$ \\
F2 & $373,6 \pm-2,4$ \\
F3 & $758,0 \pm 2,7$ \\
F4 & $1163,1 \pm 3,7$ \\
F5 & $1950,9 \pm 9,3$ \\
F6 & $4,3 \pm 0,8$
\end{tabular}

Keterangan :

F1 : Minyak atsiri biji pala konsentrasi $4 \%(\mathrm{v} / \mathrm{b})$

F2 : Minyak atsiri biji pala konsentrasi $6 \%(\mathrm{v} / \mathrm{b})$

F3 : Minyak atsiri biji pala konsentrasi $8 \%(\mathrm{v} / \mathrm{b})$

F4 : Minyak atsiri biji pala konsentrasi $10 \%(\mathrm{v} / \mathrm{b})$

F5 : Minyak atsiri biji pala konsentrasi $12 \%$ (v/b)

F6 : Kontrol

Dari Tabel IV menunjukkan formula 6 sebagai kontrol memiliki aktivitas repelan paling rendah, sedangkan formula 5 dengan minyak atsiri biji pala konsentrasi $12 \%(\mathrm{v} / \mathrm{b})$ memiliki aktivitas repelan paling tinggi. Profil aktivitas repelan dapat dilihat pada Gambar 3. Adanya minyak atsiri biji pala memberikan hasil aktivitas repelan yang lebih besar daripada tanpa adanya minyak atsiri biji pala. Terlihat bahwa aktivitas repelan yang diperoleh semakin meningkat. Semakin banyak minyak atsiri yang digunakan maka semakin tinggi aktivitas repelan yang diperoleh. Hasil analisis statistika menggunakan SPSS versi 16,0 menunjukkan hasil yang terdistribusi normal menggunakan Kolmogorof Smirnov dengan nilai signifikansi 0,604 ( $p>0,05)$ dan hasil yang homogen menggunakan Levene dengan nilai signifikansi 0,114 ( $p>0,05)$. Analisis ANOVA menunjukkan nilai signifikansi $0,000(\mathrm{p}<0,05)$ yang artinya terdapat perbedaan antar formula. Analisis menggunakan $L S D$ dari ke-6 formula diperoleh nilai signifikansi 
$0,000$ ( $\mathrm{p}<0,05)$ yang menunjukkan bahwa dari ke-6 formula berbeda signifikan sehingga diketahui dengan penambahan minyak atsiri biji pala memberikan pengaruh terhadap aktivitas repelan yang dihasilkan. Hal ini membuktikan bahwa semakin banyak minyak atsiri yang digunakan maka aktivitas repelan yang dihasilkan juga semakin meningkat. Semakin banyak minyak atsiri biji pala yang digunakan maka semakin kuat juga aroma yang dihasilkan. Aroma minyak atsiri biji pala tersebut akan mempengaruhi bau dan rasa yang berasal dari kulit sehingga dapat mencegah nyamuk untuk mendekati kulit.

\section{KESIMPULAN}

Minyak atsiri pada biji pala (Myristica fragrans Houtt.) mempunyai aktivitas sebagai repelan terhadap nyamuk Aedes aegypti betina dengan konsentrasi $12 \%$. Peningkatan konsentrasi minyak atsiri biji pala tidak memberikan pengaruh terhadap daya iritasi.

\section{UCAPAN TERIMAKASIH}

Terimakasih penulis ucapkan kepada semua pihak yang telah memberikan kontribusi selama pelaksanaan penelitian dan sampai publikasi ini. Terimakasih kepada laboran laboratorium Kimia Farmasi Universitas Ahmad Dahlan Yogyakarta yang telah membantu teknis penelitian.

\section{DAFTAR PUSTAKA}

Agoes, G., 2007, Teknologi Bahan Alam, 118, ITB, Bandung

Anonim, 2014, Pedoman Uji Toksisitas Nonklinik Secara In Vivo, Peraturan Kepala Badan Pengawas Obat dan Makanan Republik Indonesia

Du, S.S., Yang, K., Wang, C.F., You, C.X., Geng, Z.F., Guo, S.S., Deng, Z.W., and Liu, Z.L., 2014, Chemical Constituents and Activities of The Essential Oil from Myristica fragrans Against Cigarrete Beetle Lasioderma serricorne, Chemistry \& Biodiversity, 11(9): 1449

Fradin, M.S., and Day, J.F., 2002, Comparative Efficacy of Insect Repellents Against Mosquito Bites, The New England Journal of Medicine

Geetha, R.V., and Roy, A., 2014, Essential Oil Repellents-A Short Review, International Journal of Drug Development and Research, 6(2): 21

Kementerian Kesehatan Republik Indonesia, 2010, Demam Berdarah Dengue di Indonesia Tahun 1968-2009, Buletin Jendela Epidemiologi, 2(2087-1546): 5

Kementerian Kesehatan Republik Indonesia, 2015, Demam Berdarah Biasanya Mulai Meningkat di Januari, Jakarta, diunduh dari 
http://www.depkes.go.id/article/view/15011700003/demam-berdarah-biasanyamulai-meningkat-di-januari.html, diakses tanggal 19 Desember 2015

Robbins, PJ., and Cherniack, MG., 1986, Review of the biodistribution and Toxicity of the Insect Repellent N,N-diethyl-m-toluamide (DEET), J. Toxicol Environ Health, 18(4): 503-25

Tranggono, R.I., dan Latifah, F., 2007, Buku Pegangan Ilmu Pengetahuan Kosmetik, 21, PT. Gramedia Pustaka Utama, Jakarta

Yoon, J.K., Kim, K., Cho, Y., Gwon, Y., Cho, H., Heo, Y., Park, Y., Park, K., Lee, Y., Kim, M., Oh, Y., and Kim Y.B., 2015, Comparison of Repellency Effect of Mosquito Repellents for DEET, Citronella, and Fennel Oil, Journal of Parasitology Research

Yuniarsih, E., 2010, Uji Efektivitas Losion Repelan Minyak Mimba (Azadirachta indica A. Juss) Terhadap Nyamuk Aedes aegypti, Skripsi, Universitas Islam Negeri (UIN) Syarif Hidayatullah, Jakarta 